\title{
Detection of Differentially Expressed Genes in Esophageal Carcinoma Using Non-RI Differential Display with High Specificity
}

\author{
Rie Oka, ${ }^{a}$ Itaru Ninomiya, ${ }^{b}$ Hideji Tanii, ${ }^{a}$ Kouichi Miwa, ${ }^{b}$ and Kiyofumi Saijoh ${ }^{*}, a$ \\ ${ }^{a}$ Department of Hygiene and ${ }^{b}$ Second Department of Surgery, Kanazawa University School of Medicine, 13-1 Takara-machi, Kanazawa \\ 920-8640, Japan
}

(Received October 20, 2000; Accepted November 2, 2000)

\begin{abstract}
Differentially expressed genes in human esophageal carcinoma/normal tissue pairs were identified by means of a modified differential display technique to overcome the limitations of the conventional technique. Out of the eight cDNAs isolated, three were novel. The other five clones consisted of cDNA encoding cytokeratin 13, complement 7, KIAA1160, expression sequence tag (EST)-Hs110855 and EST-Hs13662. Quantitative reverse transcriptionPCR (RT-PCR) for 10 carcinoma/normal tissue pairs confirmed down-regulation of cytokeratin 13, complement 7 and KIAA1160 mRNAs in carcinoma tissue and up-regulation of EST-Hs110855 mRNA. EST-Hs13662 mRNA also seemed to increase in carcinoma tissues but not to a statistically significant extent. In situ hybridization confirmed that cytokeratin 13 mRNAs localized in differentiating keratinocytes of normal epithelia and had disappeared in carcinomas, suggesting that this down-regulation reflects de-differentiation during carcinogenesis. The functions of complement 7 and KIAA1160 mRNAs are unclear in normal tissue but their down-regulation in carcinoma tissue may help the development of esophageal carcinoma. The expression of EST-Hs110855 mRNA reportedly observed in carcinomas of different origins suggests that this EST is a carcinogenesis-related gene. Our modified technique, which eliminates the source of false-positives, reduces the screening time, and dispense with the radioisotope, was found to be useful for isolating differentially expressed genes from clinical specimens with apparently genetically distant cellular populations and a very limited mass.
\end{abstract}

Key words — differential display, esophageal carcinoma, cytokeratin 13, EST

\section{INTRODUCTION}

The prognosis for patients with esophageal carcinoma is poor, because carcinomas frequently metastasize when they invade the sub-mucosal layer of the esophagus. Although the survival of patients undergoing surgery for advanced esophageal carcinoma has improved mainly due to advances in surgical techniques and perioperative management, the 5 -year survival rate is no more than $10-40 \% .^{1)}$ To overcome difficulties in the treatment of esophageal carcinomas, understanding the biological characteristics of esophageal carcinomas and identification of their etiology are important. Epidemiological studies found that environmental exposures such as cigarette smoking, alcohol consumption, and dietary habits are risk factors for esophageal carcinomas. ${ }^{2)}$

*To whom correspondence should be addressed: Department of Hygiene, Kanazawa University School of Medicine 13-1 Takaramachi, Kanazawa 920-8640, Japan. Tel.: +81-76-265-2213, Fax: +81-76-234-4232, E-mail: saijohk@med.kanazawa-u.ac.jp
However, it is still largely unknown how these factors can cause carcinogenesis of esophageal mucosa.

Accumulation of multiple genetic changes in both oncogenes and tumor suppressor genes during tumor development has been shown in a model of colon adenocarcinoma. ${ }^{3)}$ In esophageal carcinoma, the mutation of the p53 gene $(50-70 \%),{ }^{4,5)}$ and allelic deletions of 5q21-22 implicating the apc genes $(30-70 \%),{ }^{6}$ are frequently observed. Moreover, frequent loss of heterozygosity ( $\mathrm{LOH})$ has been detected at several chromosome locations, particularly in chromosomes 4, 5, 9, 13, 17, and 18. ${ }^{7}$ However, except for chromosome 17, where p53 gene is supposed to be the primary target of allelic deletion, neither candidate tumor suppressor gene has been mapped on the LOH sites nor has it been established what kind of genetic products are encoded. Along with such genomic changes, alterations in mRNA expression have recently been reported. For example, cyclinD $1,{ }^{8)}$ alpha6 integrin, ${ }^{9)}$ polo-like kinase $(\mathrm{PLK}),{ }^{10)}$ and ErbB- ${ }^{11)}$ have been identified as genes 
showing the over-expression in esophageal carcinoma tissues compared with their normal counterparts and on the other hand, cystatin $\mathrm{B}^{12)}$ and manganese superoxide dismutase (Mn-SOD) ${ }^{13)}$ as genes showing reduction in carcinomas. Most of such mRNAs have been detected by means of differential displays using human clinical specimens. Isolation of these mRNAs could provide not only a better understanding of the biological features of tumor development but also new diagnostic markers and targets for cancer therapy.

Differential display is a sensitive technique for detecting variations in gene expression between two cellular populations. ${ }^{14)}$ However, the conventional radio-labeling differential display is plagued by false-positives. The identification of genes that are truly differentially expressed, therefore becomes a labor- and cost-intensive task. We made some modifications in the conventional technique, which was then evaluated for its ability to identify differentially expressed genes in ten carcinoma/normal tissue pairs. With this modified differential display, eight differentially expressed genes, comprising three known genes, two expression sequence tags (ESTs), and three novel genes were obtained.

\section{MATERIALS AND METHODS}

Clinical Samples and RNA Extraction - Histologically confirmed squamous cell carcinomas of the esophagus from ten patients were included in this study. All of the patients were treated by curative surgical resection with their informed consent at Kanazawa University Hospital during 1997-1998. The carcinoma and the corresponding normal specimens were immediately frozen in liquid nitrogen after resection, and kept at $-80^{\circ} \mathrm{C}$ until use. From these specimens, total RNA was prepared with the guanidium-isothiocyanated and cesium chloride method, ${ }^{15)}$ and stored at $-80^{\circ} \mathrm{C}$.

Differential Display — To circumvent individual differences of clinical specimens, pairs of normal and carcinoma mRNAs from four patients were simultaneously analyzed using differential displays. Total RNA $(2.5 \mu \mathrm{g})$ was reverse transcribed in the RT buffer containing $20 \mu \mathrm{l}$ of $0.2 \mu \mathrm{M}$ anchored poly dT primer 5'-AAGCT11V-3' (GeneHunter Corp., MA, U.S.A.), $100 \mu \mathrm{m} \mathrm{dNTPs,} \mathrm{and} 1 \mathrm{U}$ MMuLV reverse transcriptase (GeneHunter Corp.). After reverse transcription, the aliquot was diluted with $80 \mu \mathrm{l}$ of $10 \mathrm{~mm}$ Tris/HCl-1 mм EDTA (pH 8.0) and stored in $10 \mu \mathrm{l}$ each at $-80^{\circ} \mathrm{C}$ until use. Two $\mu$ of cDNA solution was subjected to PCR amplification with $10 \mu \mathrm{M}$ of one of the arbitrary primer (GeneHunter Corp.) in $50 \mu \mathrm{l}$ of $100 \mu \mathrm{M}$ dNTPs, PCR buffer, and 1U of Taq polymerase (Takara, Shiga, Japan). PCR was processed at $94^{\circ} \mathrm{C}$ for $2 \mathrm{~min}, 40^{\circ} \mathrm{C}$ for $5 \mathrm{~min}$, and $72^{\circ} \mathrm{C}$ for $5 \mathrm{~min}$ for 2 cycles, and at $94^{\circ} \mathrm{C}$ for $30 \mathrm{sec}, 55^{\circ} \mathrm{C}$ for $30 \mathrm{sec}$, and $72^{\circ} \mathrm{C}$ for $1 \mathrm{~min}$ for 28 cycles. The obtained products were separated on non-denaturing $8 \%$ polyacrylamide gels made in $16 \times 14 \mathrm{~cm}$ gel slabs. The gel was stained by $10,000-$ times diluted SYBR Green I (Molecular Probes, OR, U.S.A.) and cDNA was visualized by an imaging analyzer (Digital image analyze, Molecular Dynamics, U.S.A.). The bands showing reproducible differential expression were excised and the precise excision was confirmed again by imaging analyzer. The cDNA fragments was extracted by boiling, PCR reamplified, subcloned into pGEM-T vector (Promega, Madison, WI, U.S.A.). The obtained clones were sequenced with a dRhodamine Terminator Cycle Sequencing Kit (Applied Biosystems, Norwalk, CT, U.S.A.) and analyzed using the GenBank BLAST and FAST homology search programs. The cloned P4 cDNA was also utilized to generate probes for in situ hybridization.

\section{Quantitative Reverse Transcription (RT)-PCR}

RT-PCR was utilized for quantitaion of mRNAs as described elsewhere. ${ }^{16)}$ Briefly, oligodT-primed cDNA from $0.2 \mu \mathrm{g}$ of total RNA was subjected to PCR processed at $94^{\circ} \mathrm{C}$ for $1 \mathrm{~min}, 61^{\circ} \mathrm{C}$ for $1 \mathrm{~min}$, and $72^{\circ} \mathrm{C}$ for $1 \mathrm{~min}$. The sequences of the primers used were as follows: P2, upstream (5'TGGGCCCTCAGGATGTTTCAA- $3^{\prime}$ ) and downstream (5'-GCCGGCTTTGTTTTGTCTCAC-3); P4, upstream (5'-GAGGAATGGTTCCACGCCAAG- $\left.3^{\prime}\right)$ and downstream (5'-GCGACCAGAGGCATTAGAGGT-3); P5, upstream (5'CAGTCCTGCCACTTTCACTAAGGTACCCAAAAGCCCTA- ${ }^{\prime}$ ) and downstream (5'-CTAGAAGGTGAGTGTCAGTTC-3); P7, upstream (5'ATGTCAGCGCTGGGAGAAACT- ${ }^{\prime}$ ) and downstream (5'-CAAGGACTTATGCTGGTGACA-3); P8, upstream (5'-GCAGTCACTCTCAGAATCTTG-3') and downstream (5'-GCTGTGATTCCACATCAAACC-3); glyceraldehyde 3-phosphate dehydrogenase (GAPDH), upstream (5'-CATGGGGAAGGTGAAGGTCGGA-3'), and downstream (5' TTGGCTCCCCCCTGCAAATGAG-3'). The PCR products were separated by electrophoresis on a $2 \%$ agarose-ethidium bromide gel and visualized under UV light. Camera images were converted to PICT 
files and analyzed using the NIH image 1.55 program. The mRNA expression of P2, P4, P5, and P8 was estimated by means of standardization with that of GAPDH as the internal control for each sample. In Situ Hybridization — The P4 cDNA clone obtained by differential display was linealized by restriction enzyme digestion using NcoI or SalI. From the linealized clone, the bidirectional cRNA probes were obtained using either T7 or SP6 RNA polymerase (Takara) and the DIG Labeling Kit (Boehringer, Mannheim, Germany). Frozen samples were cut into $4 \mu \mathrm{m}$ sections, mounted on coated glass slides, and fixed with $4 \%$ paraformaldehyde in $0.1 \mathrm{M}$ phosphate buffer for $15 \mathrm{~min}$. The sections were then treated with $0.2 \mathrm{~N} \mathrm{HCl}$, acetylated with $0.25 \%$ acetic anhydride in $0.1 \mathrm{~m}$ triethanolamine, $\mathrm{pH} 8.0$, for $10 \mathrm{~min}$, dehydrated with ethanol series, and air dried. After prehybridization with the hybridization solution containing $50 \%$ formamide, $10 \%$ dextran sulfate, $1 \times$ Denhardt's solution, $600 \mathrm{~mm} \mathrm{NaCl}, 0.25 \%$ SDS, $150 \mu \mathrm{g} / \mathrm{ml}$ yeast tRNA at $50^{\circ} \mathrm{C}$ for $2 \mathrm{hr}$, each slide was allowed to hybridize with approximately $0.5 \mu \mathrm{g} / \mathrm{ml}$ of the cRNA probe for $16 \mathrm{hr}$ at $50^{\circ} \mathrm{C}$. The slides were washed briefly in $5 \times \mathrm{SSC}^{15)}$ at ambient temperature and in $50 \%$ formamide and $2 \times \mathrm{SSC}$ at $50^{\circ} \mathrm{C}$ for $30 \mathrm{~min}$, treated with $10 \mu \mathrm{g} / \mathrm{ml} \mathrm{RNase} \mathrm{A}$ at $37^{\circ} \mathrm{C}$ for $30 \mathrm{~min}$ and again washed once with $2 \times$ SSC and twice with $0.2 \times$ SSC for 20 min each at $50^{\circ} \mathrm{C}$. After hybridized digoxigenin-labeled probes were detected with the Nucleic Acid Detection Kit (Boehringer), the slides were rinsed with $10 \mathrm{~mm}$ Tris- $\mathrm{HCl}, \mathrm{pH} 8.0$ and $1 \mathrm{~mm}$ EDTA, and fixed.

Statistical Analysis — The statistical significance of differences in the mRNA expression between carcinoma/normal tissue pairs was calculated using Wilcoxon's signed rank test.

\section{RESULTS}

\section{Isolation of Differentially Expressed Gene}

When the PCR products of differential display were electrophoresed, each lane consisted of about 20-30 bands (Fig. 1). Most bands showed the same intensities between carcinoma and normal samples in all four cases. However, bands seen in all normal samples were substantially reduced or had disappeared in all carcinoma samples (Fig. 1, F1 \& F3) and vice versa (Fig. 1, F2). Differential display using 20 arbitrary primers could isolate 14 cDNAs which showed differential expression in all of the four tissue pairs, and eight of these cDNAs could be

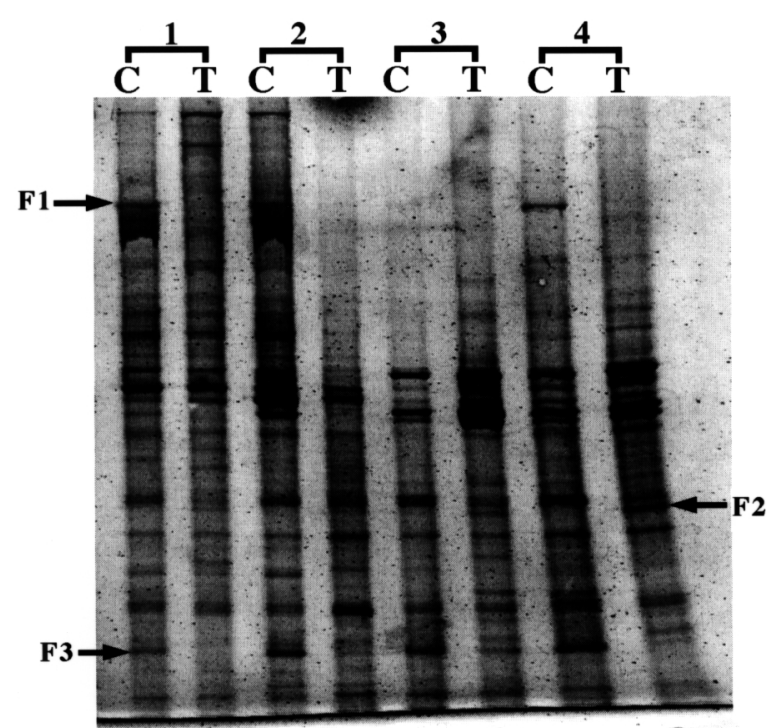

Fig. 1. Differential Display of mRNAs from Esophageal Carcinoma and Normal Tissues

mRNAs of carcinoma/normal pairs from four patients were analyzed by differential display using a set of primers; AAGCT11C (5'AAGCTTTTTTTTTTTC-3') and AP61 (5'-AAGCTTGACCTTT-3'). F1, F3, fragments appeared in normal tissues but decreased or almost absent in carcinoma tissues; F2, fragments appeared in carcinoma tissues but not in their normal counterparts; N, Normal tissue; C, carcinoma tissue.

reamplified, cloned, and subjected to sequence analysis (Table 1). A homology search showed that two cDNAs matched those encoding cytokeratin 13 for P4 and complement 7 for P7 (Table 2). Three cDNAs, P2, P5, and P7, were EST or KIAA with unknown function. In addition, three novel cDNAs were isolated, which were registered as ESTs.

\section{Quantitation of Differentially Expressed mRNAs Using Quantitative RT-PCR}

The amounts of mRNAs, except for those of the novel ones in ten carcinoma/normal tissue pairs were estimated by means of quantitative RT-PCR. A preliminary study disclosed that the intensity of PCR products for GAPDH increased linearly from 20 to 28 cycles in both normal and carcinoma tissues (Fig. 2, A and B). The 447-bp-products for P4 cDNA appeared at 22 cycles and increased linearly from 24 to 30 cycles in normal tissue, while those in carcinoma tissue were faint even at 32 cycles. When the intensities of bands were plotted against cycles, 28 cycles showed exponential amplification both in carcinoma and normal tissues (Fig. 2, C). The expression of $\mathrm{P} 4 \mathrm{cDNA}$ was therefore assessed as the intensity of products at 28 cycles over that of GAPDH at 24 cycles (Fig. 2, D). This procedure was 
Table 1. Partial Sequences of ddPCR Products Differentially Displayed between Esophageal Carcinoma and Its Normal Counterparts

\begin{tabular}{|c|c|c|}
\hline Product & sequence $^{a)}$ & Accession no. \\
\hline $\mathrm{P} 1$ & $\begin{array}{l}\text { acctaatgtcccatgacatcccatggggatcagatactgaatttagcttccttgtttgtcccagttcagaaaatgagttgttc } \\
\text { attgttctaaacttattagatgacttacatgtgacngttacaggctgttgcttatgggaacatattaagggcattgaggag }\end{array}$ & BF219668 \\
\hline $\mathrm{P} 2$ & $\begin{array}{l}\text { gccagccgagectctctctctgctttccacttttccactaactcggetctgagtttcttttcatattcctgttccaaaggcaca } \\
\text { ataacaccatcatcttcatctaggtaaccatagtactcaaaatcgattg }\end{array}$ & BF219669 \\
\hline P3 & $\begin{array}{l}\text { ctcattaaatatatcgcggacactcttttctaatacatctgacatattcacctcacagtgtcattaccgtatatagcggtcatt } \\
\text { gattttctcgtcgagcagtttaattcttagaagaatttcatcgatttttgacttttcaacagtaccattcatataatggtctataa } \\
\text { gccaaaaataataattgattaaacggggcacaagaagtttcttgttttttacgtccttctctctcagctcattttcaagcatat } \\
\text { agatggactgcttcagcttccccagttccaaggctttcagttcacgttttacattgagtacgccgtccagcgtaccataaa } \\
\text { ccggaagccattctaacaactcctctcctgtataaccgttgtttgcgactttagtaacgagc }\end{array}$ & BF219670 \\
\hline $\mathrm{P} 4$ & $\begin{array}{l}\text { cctgagagcagagggactgagccttgggtccagcagccctcctctctcctgcagggaactgccggctctctcctcct } \\
\text { ctgggtgctgaagacagagggaggggacgccaggcagatttaaggectacggacatcagaagtgcggcgaccag } \\
\text { aggcattagaggtggtggtaacagaggcactagaagtcgtggtaacagaggtgctacgggggetgacgcttcctgg } \\
\text { gaaacaagagacaagacatgctcaggctggagaagacccacctcaggacagggcagggccccctggagggctc } \\
\text { acaaactcctcattagtcaggtggtgcgtggat }\end{array}$ & BF219671 \\
\hline P5 & cttttaataacaagactaactgtaccagtgactgataacatcctgaataaagactgcaatacccacattct & BF219672 \\
\hline P6 & $\begin{array}{l}\text { taaaanccttggcctnccatcaaaacntaatgtaaacaatagtttttccatgggttcagatttaatttttacaccaaagcca } \\
\text { aaggcgacntggttaatnttgagcaccttttatgccatttttgtatttngcagatgaagcaagtgtagaattaatgcntaac } \\
\text { ttgattgcgagcatcnncncaagcggentgatagaaaaatcaagaccaataccgtatttactatgcagtgcaggatcc } \\
\text { gctttttttgcattataagctaaataataaccggcatcaagcttccacttttcataatagatggtcttagttatcatattaagcc } \\
\text { atatntcaccggctggaactctcaattcattctttacatccgtattagttacattacgccg }\end{array}$ & BF219673 \\
\hline $\mathrm{P} 7$ & $\begin{array}{l}\text { gaagaatagcatcttaatgagtgttctaatccttgtcatctgaagttttgaaatatatttaccagggtcagaacaatacaga } \\
\text { gatagtatttgtataatatagcttattttaaatttcatttaagccctctcatttctcctcccacagctgctgttttgttttgatgaaa } \\
\text { gagaaataaggaataaata }\end{array}$ & BF219674 \\
\hline P8 & $\begin{array}{l}\text { aaaggaccatngtttggtgggagtacagggtaggaggatgaggaaaacaagaagggagctggagatttggccaag } \\
\text { gagcaacttcagaaggacaggagagcacgagcattaggaggaagcc }\end{array}$ & BF219675 \\
\hline
\end{tabular}

a) Recognition sequences are given using single-letter International Union of Pure and Applied Chemistry codes and standard abbreviations to represent ambiguity $(n=\mathrm{a}, \mathrm{c}, \mathrm{g}$, or $\mathrm{t})$.

Table 2. Identification of the ddPCR Amplification Products Differentially Displayed between Tumor and Normal Tissues of the Esophagus

\begin{tabular}{|c|c|c|c|c|c|}
\hline \multirow{2}{*}{ Produc } & \multirow{2}{*}{$\begin{array}{l}\text { ddPCR } \\
\text { primers }\end{array}$} & \multicolumn{2}{|c|}{ Amplification extent } & \multirow{2}{*}{ Homology search } & \multirow{2}{*}{$\begin{array}{l}\text { Accession } \\
\text { number }\end{array}$} \\
\hline & & Normal & Tumor & & \\
\hline $\mathrm{P} 1$ & dT11 C/AP-53 & - & + & No match & \\
\hline P2 & dT11 C/AP-56 & ++ & - & KIAA1160 & Hs.33122 \\
\hline P3 & dT11 A/AP-61 & - & + & No match & \\
\hline P4 & dT11 C/AP-61 & ++ & - & cytokeratin 13 & X14640 \\
\hline P5 & dT11 G/AP-62 & - & ++ & EST & Hs. 110855 \\
\hline P6 & dT11 A/AP-54 & + & ++ & No match & \\
\hline P7 & dT11 G/AP-52 & ++ & - & complement 7 & Hs.78065 \\
\hline P8 & AP-62/AP-62 & + & ++ & EST & Hs. 13662 \\
\hline \multicolumn{6}{|c|}{$\begin{array}{l}\text { A selection of } 8 \text { ddPCR products showing differentilly expressed } \\
\text { pattern between tumor and normal tissues were isolated from non- } \\
\text { denaturating acrylamide gels, reamplified, and sequenced in both di- } \\
\text { rections using the corresponding primers. The sequences were con- } \\
\text { fronted to EMBL/GenBank databases using the Blast algorithms to } \\
\text { search for homology with existing sequences. }\end{array}$} \\
\hline
\end{tabular}

also found to be suitable for estimation of other mRNAs. Expression of P4 mRNA, namely cytokeratin $13 \mathrm{mRNA}$, in normal tissue was $0.18 \pm 0.10$ times as much as that of GAPDH mRNA and that in carcinoma tissue was significantly reduced to $0.02 \pm 0.01$ (Fig. 3). The carcinoma/normal ratio ( $\mathrm{T} / \mathrm{N}$ ratio) was $0.10 \pm 0.03$ on average. Complement 7 mRNA, i.e. P7 mRNA, was expressed $0.08 \pm 0.01$ times as much as that of GAPDH mRNA in normal tissue. Although the $\mathrm{T} / \mathrm{N}$ ratio was higher than 1 in one case, its reduction in carcinoma tissue was statistically significant, at $0.43 \pm 0.05$. Constitutive expression of P2 mRNA, KIAA1160 mRNA, was also observed in normal tissue, $0.12 \pm 0.01$ times more than that of GAPDH mRNA and its reduction in carcinoma tissue was also significant even though two cases had a $\mathrm{T} / \mathrm{N}$ ratio of more than 1. The increase in P5 mRNA, ESTHs110855, in carcinoma tissue was statistically significant because seven out of ten normal tissues displayed a very low expression, while the expression in the remaining three tissues was almost the same as that in carcinoma tissue. Although P8, ESTHs13662, was selected as being enriched in carcinoma tissues, the increase was not always statistically significant. For the novel cDNAs, primers suitable for quantification were unfortunately not avail- 


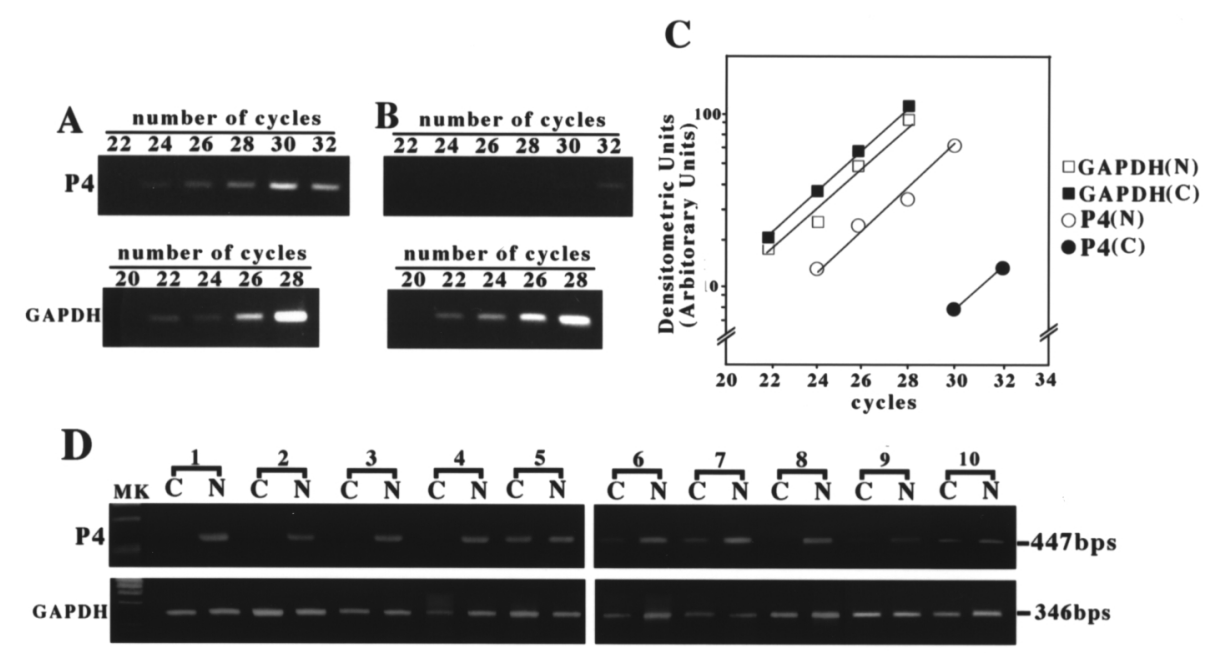

Fig. 2. Semi-Quantitative RT-PCR Analysis of mRNA Expression of P4 in Paired Normal/Carcinoma Tissue Pairs

Increases in RT-PCR products for P4 and GAPDH according to PCR cycles in the normal (A) and the carcinoma (B) tissue from case 1. C: The intensities of the bands based on the PCR cycle number were plotted. D: mRNA expression was measured at of 28 cycles of PCR amplification for P4 and at 24 cycles for GAPDH.
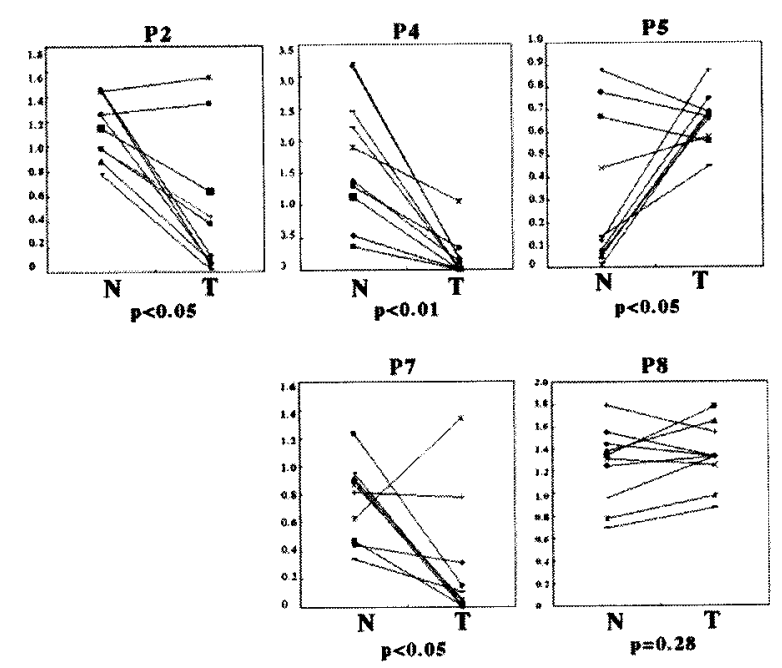

Fig. 3. Confirmation of Differential Expression of the Genes Obtained by Differential Display

Expression is given as $\times 10^{-1}$ of GAPDH mRNA expression. Statistical differences between normal $(\mathrm{N})$ and carcinoma $\mathrm{C}$ ) tissues were calculated using Wilcoxon's signed rank test.

able.

\section{In Situ Hybridization Analysis for P4 mRNA}

In situ hybridization demonstrated that the antisense cRNA probe for P4 mRNA was hybridized to the cells in the suprabasal layers of normal esophageal epithelia (Fig. 4). The signal intensity was especially strong in the parabasal regions and became weaker toward the surface. No positivity was observed in the basal cells of epithelia and sub-epithelial cells, nor was antisense or sense cRNA posi-

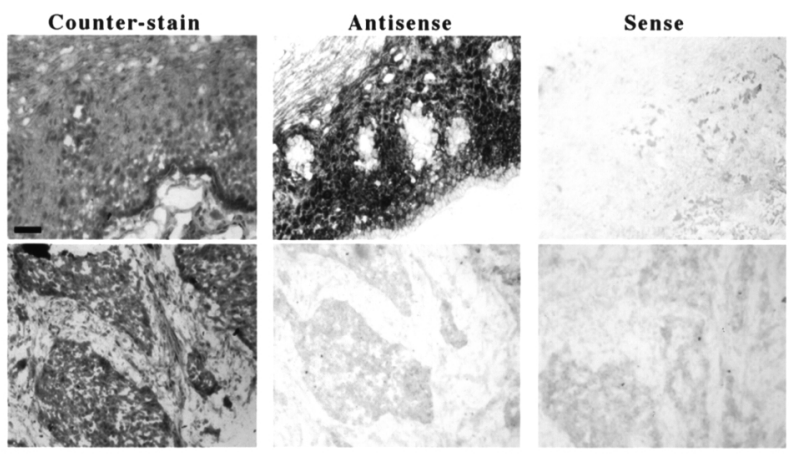

Fig. 4. Localization of $\mathrm{P} 4$ mRNAs in the Normal Esophageal Tissue and in the Carcinoma Tissue Determined by in Situ Hybridization

Upper panels show the normal esophageal mucosa and lower panels the carcinoma tissue. Serial sections were stained by hematoxylin, antisense probe, and sense probe. The bar indicates $150 \mu \mathrm{m}$.

tive for carcinoma tissue.

\section{DISCUSSION}

By means of differential display using carcinoma/normal tissue pairs of esophagus, a total of eight cDNAs were cloned as differentially expressed genes. Further quantitative RT-PCR confirmed that cytokeratin 13, complement 7 and KIAA1160 mRNAs were constitutively expressed in normal esophagus and their expression reduced in carcinoma tissue. EST-Hs 13662 expression was not statistically significant but seemed to increase more in carcinoma 
tissue than in normal tissue. On the other hand, the elevation on EST-Hs110855 mRNA in carcinoma tissue was statistically significant, while its expression was high in three normal tissues.

Differential display is useful for isolating differentially expressed genes in more than two cellular populations, ${ }^{14)}$ and helps the isolation of not only known mRNAs with specific functions for their originating cells, but also novel mRNAs whose function is not yet clear. Specifically, the number of genes related to cell cycles could be isolated by means of differential display. ${ }^{17)}$ The conventional radiolabeling differential display is extremely sensitive but includes many false-positives, lack of $3^{\prime}$ end representation and redundancy between cDNA subsets. These problems are the result of low annealing temperature of primers, inhibition of polymerase activity by radioisotopes, pseudo-amplification during extraction/cloning procedure from denaturing acrylamide gels, and other characteristics. Such difficulties are especially noticeable when the populations are genetically distant as in carcinoma/normal tissue pairs. In the study presented here, we made three modifications to the conventional differential display. First, amplified products underwent further analysis only when their differential expression was confirmed in multiple carcinoma/normal tissue pairs. Although Northern blot analysis, reverse Northern blot analysis and other procedures so on are used to confirm reproducibility in the conventional differential display, these methods are not only time consuming but also sometimes less sensitive than the differential display itself. Moreover, they can be performed only when a great deal of RNA is available. Second, the products were not labeled by radioisotopes during amplification but stained with SYBR green after electrophoresis. Finally, the products were separated on non-denaturing acrylamide gels, which were easy to handle compared with denaturing gels. SYBR green staining was not always as sensitive as radioisotope labeling but not using radioisotopes avoids impairment of polymerase activity so that longer cDNAs can be obtained with high fidelity. Moreover, cDNA destruction caused by radioisotopic decay during storage could be avoided. In fact, only 14 bands in our study were of interest although 20 arbitrary primes were used. Out of these 14, eight cDNAs (57\%) could be isolated. In a previous study at our department, it was found that conventional radio-labeling differential display using ten arbitrary primers could amplify 280 candidate bands, but only ten of these were confirmed to be truly differentially expressed. ${ }^{18)}$ In addition, eight out of the ten were mitochondrial or ribosomal so that only two cDNAs seemed to be functionally significant.

Among cDNAs enriched in normal tissue but down-regulated in carcinoma tissue, cytokeratin 13 belongs to the family of intermediate filament protein which is expressed mostly in epithelial cells and associated with cytoskeleton organization. Cytokeratins are consisted of acidic type I (K9-20) and basic type II (K1-8). ${ }^{19)}$ Specific combinations of type I and II are expressed depending on their developmental and differentiation status. ${ }^{20)}$ The finding that cytokeratin 13 mRNA originated from the suprabasal layers of normal esophageal epithelia but decreased toward the surface agrees with the result of a immunohistochemical analysis demonstrating that $\mathrm{K} 5 / \mathrm{K} 14$ are expressed in proliferating basal cells but that once they detach from the basal layer, they are replaced with K4/K13 in the internal non-cornified epithelia. ${ }^{21)}$ Moreover, its down-regulation in carcinoma tissue indicates that the loss of cytokeratin 13 immunoreactivity ${ }^{22}$ ) occurred transcriptionally and that its expression regulation was associated with de-differentiation during carcinogenesis.

Although complements have been considered to be serum proteins of hepatic origin, the allotypic changes occurring from transplant recipients to its donors quantifies that approximately $30 \%$ of systemic complement 7 is derived from non-marrow/ non-hepatic organs. ${ }^{23)}$ Although the contribution of esophageal complement 7 mRNA to this non-marrow/non-hepatic pool is unknown, the normal esophagus is, in any case, one of the local origins of complement 7 . In addition to the esophagus, preferential expression of complement 7 mRNA was reportedly observed in colon, heart, brain etc. ${ }^{24)}$ although the function of locally expressed complement 7 is still unclear. The esophagus is continuously exposed to external stimulation and the expression of complement components is known to be induced by cytokines. ${ }^{25)}$ It is important to clarify whether the preferential expression in normal tissue is truly constitutive or is induced by such stimulation. It is also considered important to explore whether the downregulation in carcinoma tissue is associated with carcinogenesis itself or is the result of changes in microenvironments including cytokines.

KIAA1160, supposedly encoding a protein consisting of 350 amino acids, has been isolated from the human brain library to target the coding sequence of large proteins from long mRNAs. Although 
KIAA1160 mRNA was found to localize ubiquitously among tissues, its function remains unknown. EST-Hs 13662 was also found to localize ubiquitously, while EST-Hs110855 is reportedly characterized by relatively limited localization in germ cells, renal cell carcinoma, colon adenocarcinoma, etc. Hence, the transcriptional regulation of ESTHs 110855 seems to be more closely related to carcinogenesis than that of EST-Hs 13662 and KIAA1160. Isolation of the full length cDNA sequence as well as the promoter sequence of ESTHs110855 should provide essential information about carcinogenesis-associated alteration in gene expression regulation and the resulting phenotypic changes in carcinoma tissue.

Acknowledgements We thank to Dr. Dang at Tokyo University for his technical suggestions. This work was supported in part by a Grand-in-Aid from the Ministry of Education, Science, and Culture, of Japan (C2-11670412 and A-11770180) and Hokkoku-gann-kikinn, '98.

\section{REFERENCES}

1) Ando, N., Ozawa. S., Kitagawa, Y., Shinozawa, Y. and Kitajima, M. (2000) Improvement in the results of surgical treatment of advanced squamous esophageal carcinoma during 15 consecutive years. Ann. Surg., 232, 225-232.

2) Yu, M. C., Garabrant, D. H., Peters J. M., Mack, T. M. (1988) Tobacco, alcohol, diet, occupation, and carcinoma of the esophagus. Cancer Res., 48, 38433848.

3) Cho, K. R. and Vogelstein, B. (1992) Genetic alterations in the adenoma-carcinoma sequence. Cancer, 70, 1727-1731.

4) Greenblatt, M. S., Bennett, W. P., Hollstein, M. and Harris, C. C. (1994) Mutations in the p53 tumor suppressor gene: clues to cancer etiology and molecular pathogenesis. Cancer Res., 54, 48554878.

5) El-Deiry, W. S., Tokino, T., Velculescu, V. E., Levy, Hollstein, M. C., Metcalf, R. A., Welsh, J. A., Montesano, R. and Harris, C. C. (1990) Frequent mutation of the p53 gene in human esophageal cancer. Proc. Natl. Acad. Sci. U.S.A., 87, 9958-9961.

6) Shibagaki, I., Shimada, Y., Wagata, T., Ikenaga, M., Imamura, M. and Ishizaki, K. (1994) Allelotype analysis of esophageal squamous cell carcinoma. Cancer Res., 54, 2996-3000.

7) Montesano, R., Hollstein, M. and Hainaut, P. (1996)
Genetic alterations in esophageal cancer and their relevance to etiology and pathogenesis: a review. Int. J. Cancer., 69, 225-235.

8) Kanda, Y., Nishiyama, Y., Shimada, Y., Imamura, M., Nomura, H., Hiai. H. and Fukumoto, M. (1994) Analysis of gene amplification and overexpression in human esophageal-carcinoma cell lines. Int. J. Cancer., 58, 291-297.

9) Tanaka, Y., Mimori, K., Shiraishi, T., Ohkura, Y., Takubo, K., Mafune, K., Barnard, G. F. and Mori, M. (2000) Alpha6 integrin expression in esophageal carcinoma. Int. J. Oncol., 16, 725-729.

10) Tokumitsu, Y., Mori, M., Tanaka, S., Akazawa, K., Nakano, S. and Niho, Y. (1999) Prognostic significance of polo-like kinase expression in esophageal carcinoma. Int. J. Oncol., 15, 687-692.

11) Tanaka, S., Mori, M., Akiyoshi, T., Tanaka, Y., Mafune, K., Wands, J. R. and Sugimachi, K. (1997) Coexpression of Grb7 with epidermal growth factor receptor or Her2/erbB2 in human advanced esophageal carcinoma. Cancer Res., 57, 28-31.

12) Shiraishi, T., Mori, M., Tanaka, S., Sugimachi, K. and Akiyoshi, T. (1998) Identification of cystatin B in human esophageal carcinoma, using differential displays in which the gene expression is related to lymph-node metastasis. Int. J. Cancer., 79, 175-178.

13) Toh, Y., Kuninaka, S., Mori, M., Oshiro, T., Ikeda, Y., Nakashima, H., Baba, H., Kohnoe, S., Okamura, T. and Sugimachi, K. (2000) Reduced expression of manganese superoxide dismutase mRNA may correlate with invasiveness in esophageal carcinoma. Oncology, 59, 223-228.

14) Liang, P. and Pardee, A. B. (1992) Differential display of eukaryotic messenger RNA by means of the polymerase chain reaction. Science, 257, 967971.

15) Maniatis, T., Fritsch, E. F. and Sambrook, J. (1989) Molecular cloning: A Laboratory Manual. Cold Spring Harbor Press, Cold Spring Harbor.

16) Fujii, S., Honda, S., Sekiya, Y., Yamasaki, M., Yamamoto, M. and Saijoh, K. (1998) Differential expression of nitric oxide synthase isoforms in formdeprived chick eyes. Curr. Eye. Res., 17, 586-593.

17) Alpan, R. S., Sparvero, S. and Pardee, A. B. (1996) Identification of mRNAs differentially expressed in quiescence or in late $\mathrm{G} 1$ phase of the cell cycle in human breast cancer cells by using the differential display method. Mol. Med., 2, 469-478.

18) Fujii, S., Escano, M. F., Ishibashi, K., Fujii, M., Sekiya, Y., Yamamoto, M. and Saijoh, K. (2000) Differential expression of neuroendocrine-specific protein in form-deprived chick eyes. Invest Ophthalmol. Vis. Sci., 41, 1533-1541.

19) Fuchs, E. and Weber, K. (1994) Intermediate 
filaments: structure, dynamics, function, and disease. Annu. Rev. Biochem., 63, 345-382.

20) Quinlan, R. A., Schiller, D. L., Hatzfeld, M., Achtstatter, T., Moll, R., Jorcano, J. L., Magin, T. M. and Franke, W. W. (1985) Patterns of expression and organization of cytokeratin intermediate filaments. Ann. N. Y. Acad. Sci., 455, 282-306.

21) Viaene, A. I. and Baert, J. H. (1995) Expression of cytokeratin mRNAs in normal human esophageal epithelium. Anat. Rec., 241, 88-98.

22) Takahashi, H., Shikata, N., Senzaki, H., Shintaku, M. and Tsubura, A. (1995) Immunohistochemical staining patterns of keratins in normal oesophageal epithelium and carcinoma of the oesophagus.
Histopathology, 26, 45-50.

23) Naughton, M. A., Walport, M. J., Wurzner, R., et al. (1996) Organ-specific contribution to circulating C7 levels by the bone marrow and liver in humans. Eur. J. Immunol., 26, 2108-2112.

24) Azin, A., Michael, C., Montalto, C. L., et al. (2000) Isolation, Characterization, and Cloning of Porcine Complement Component C7. J. Immunol., 165, 1059-1065.

25) Gerritsma, J. S., Gerritsen, A. F., De Ley, M., van Es, L. A. and Daha, M. R. (1997) Interferon-gamma induces biosynthesis of complement components $\mathrm{C} 2, \mathrm{C} 4$ and factor $\mathrm{H}$ by human proximal tubular epithelial cells. Cytokine., 9, 276-283. 